\title{
On the persistence of adiabatic shear bands
}

\author{
S. Boakye-Yiadom, M.N. Bassim, and S. Al-Ameeri \\ University of Manitoba Faculty of Engineering, Winnipeg, Canada
}

\begin{abstract}
It is generally agreed that the initiation and development of adiabatic shear bands (ASBs) are manifestations of damage in metallic materials subjected to high strain rates and large strains as those due to impact in a Hopkinson Bar system. Models for evolution of these bands have been described in the literature. One question that has not received attention is how persistent these bands are and whether their presence and effect can be reversed or eliminated by using a process of thermal (heat treatment) or thermo-mechanical treatment that would relieve the material from the high strain associated with ASBs and their role as precursors to crack initiation and subsequent failure. Since ASBs are more prevalent and more defined in BCC metals including steels, a study was conducted to investigate the best conditions of generating ASBs in a heat treatable steel, followed by determining the best conditions for heat treatment of specimens already damaged by the presence of ASBs in order to relieve the strains due to ASBs and restore the material to an apparent microstructure without the "scars" due to the previous presence of ASBs. It was found that heat treatment achieves the curing from ASBs. This presentation documents the process undertaken to achieve this objective.
\end{abstract}

\section{Introduction}

Adiabatic shear bands have been observed during deformation of metallic materials, including metal matrix composites and in high strength ceramics [1-4]. They consist of narrow bands that form as the metal is exposed to high strain rates and large strains and they are caused by two competing mechanisms, namely an initial strain hardening followed by thermal softening due to adiabatic heating as a result of impact [5]. This leads to stress collapse and the initiation of ABSs. After initiation, adiabatic shear bands may propagate as single bands or multiple bands with defined spacing between these bands. Depending on the geometry of the specimen or component, ASBs propagate in parabolic trajectories in three dimensions forming cones within the material.

Other features associated with ASBs are that they either may be deformed or transformed ASBs (or a combination of both). It was found that this feature is more prevalent in body centered cubic metals (BCC) such as high strength steels [6] while face centered cubic metals (FCC) are more inclined to exhibit diffuse adiabatic shear bands with an appearance of plastic flow as opposed to the well defined shear bands in BCC metals.

White adiabatic shear bands have been predominantly studied in metallic and other materials for use as armour plate materials in military applications [7]. Other occurrences of adiabatic shear bands can be found in manufacturing processes such as rolling, high speed machining, friction welding, and explosive welding [8]. It has also been observed in friction and wear of premium rails due to friction [9]. In their application, ASBs are either tolerated in the piece or grinded out mechanically, such as in grinding the face of the rails to eliminate ASBs and consequent crack formation in the rail.

The issue of eliminating ASBs without destroying the manufactured component brings into question the persistence of adiabatic shear bands as an indication of damage and whether a thermal treatment, i.e. annealing or a thermo-mechanical heat treatment may eliminate or at least reduce the influence of ASBs as manifestation of damage in the material before fracturing and collapse takes place. While the mechanism of formation and propagation of initial ASBs on a microscopic and mesoscale level remains under research investigation using recently developed electron microscopy techniques, the present research addresses this question by investigating the mutual occurrence of ASBs in a heat treatable steel, followed by a thermal treatment of the impacted steel and observation of the changes in microstructure using optical microscopy and changes in hardness within the adiabatic shear bands. Thus, an initial answer to whether ASBs are persistent feature of high strain rate and large strain deformation or can their damaging effect be reduced or may be eliminated by the proper heat treatment.

\section{Experimental procedure}

The steel used in this investigation was a heat treatable AISI 4340 steel (C: $0.38-0.43 \%$, Mn $0.6-0.8 \%$, Si $0.15-$ $0.35 \%$, Cr $0.7-0.9 \%$, Mo $0.2-0.3$, Ni $1.65-2.00 \%)$. The steel was obtained in rod form and was cut and machined into cylindrical test pieces. An initial heat treatment was carried out by austenitizing at $843^{\circ} \mathrm{C}$ for 30 minutes followed by oil quenching to obtain fully martensitic microstructure. The specimens were then tempered at temperatures $315^{\circ} \mathrm{C}, 425^{\circ} \mathrm{C}$ and $620^{\circ} \mathrm{C}$ for one to two hours. They were next tested using a direct impact split Hopkinson compression bar at different projectile velocities resulting in several impact momentums. Stress strain curves for the specimens tested were obtained from strain gage outputs verses time.

The impacted specimens were next cut, grinded, polished and etched. They were examined in an optical microscope to determine the best conditions for obtaining well-defined adiabatic shear bands not containing microcracks. Micro hardness (HV) was also measured in the specimen containing acceptable shear bands. 


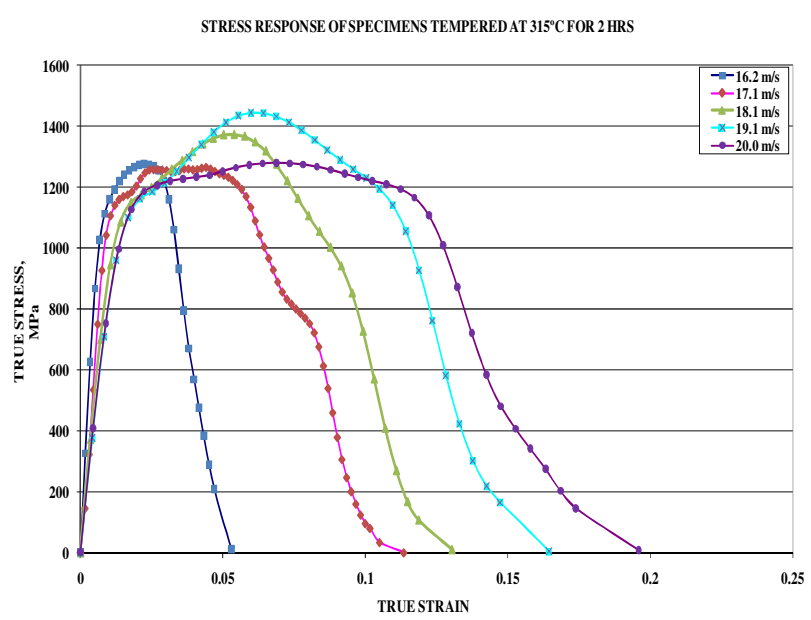

Fig. 1. Stress response of specimens tempered at $315^{\circ} \mathrm{C}$ for 2 hours.

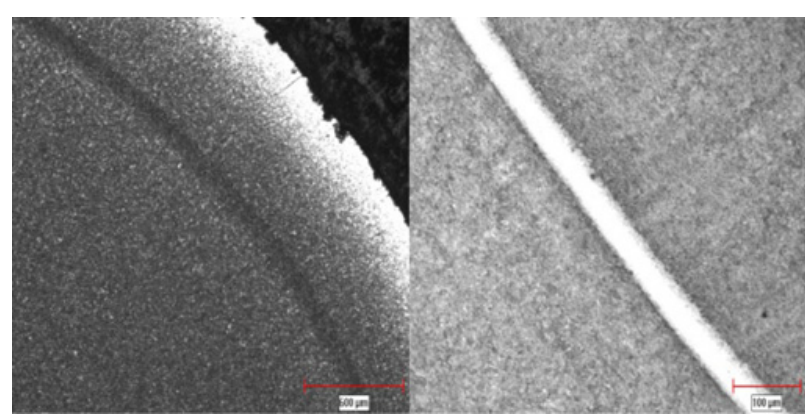

Fig. 2. A specimen after impact showing a (a) deformed band (b) transformed band.

The impacted specimens were next subjected to heat treatments at temperatures $350^{\circ} \mathrm{C}, 450^{\circ} \mathrm{C}, 650^{\circ} \mathrm{C}$ and $850^{\circ} \mathrm{C}$ for times ranging from 30 minutes to four hours. Afterwards, they were examined using optical microscopy and measurements of the microhardness to investigate the effect of heat treatment on the persistence of the adiabatic shear bands developed earlier.

\section{Experimental results}

A typical stress-strain curve obtained after impact of specimens tempered at $315^{\circ} \mathrm{C}$ for 2 hours is shown in figure 1 .

The stress response graphs are indicative of the behavior of the specimens and their respond to deformation. The flow stress increases initially with strain, reaches a maximum and decreases with subsequent increase in strain.

Some of the adiabatic shear bands obtained after impact are shown in figure 2. The adiabatic shear bands observed may be either a deformed or a transformed band as shown on figure 2 .

In the current study, it was observed that although impact momentum and strain rates affect the formation of shear bands, the initial condition (tempering temperature and time) of the steel specimens before impact also has a significant influence on the formation of the shear bands. Tempering the specimens at $315^{\circ} \mathrm{C}$ and $425^{\circ} \mathrm{C}$ for $1 \mathrm{hr}$ led

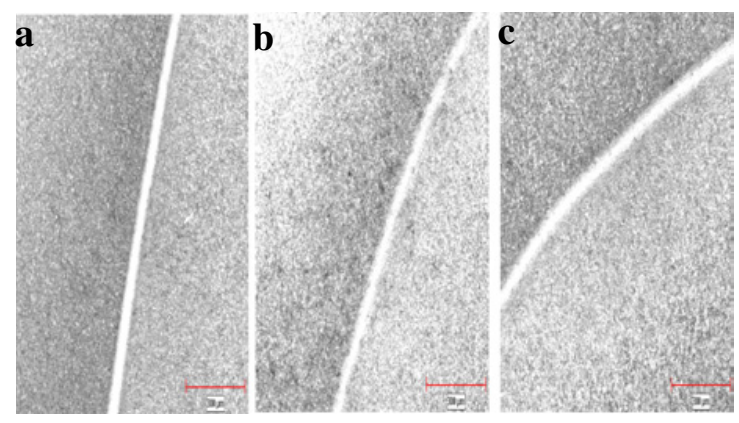

Fig. 3. Steel specimen (a) after impact (b) after 2 hrs post-impact annealing at $350^{\circ} \mathrm{C}(\mathrm{c})$ after $4 \mathrm{hrs}$ post-impact annealing at $350^{\circ} \mathrm{C}$.

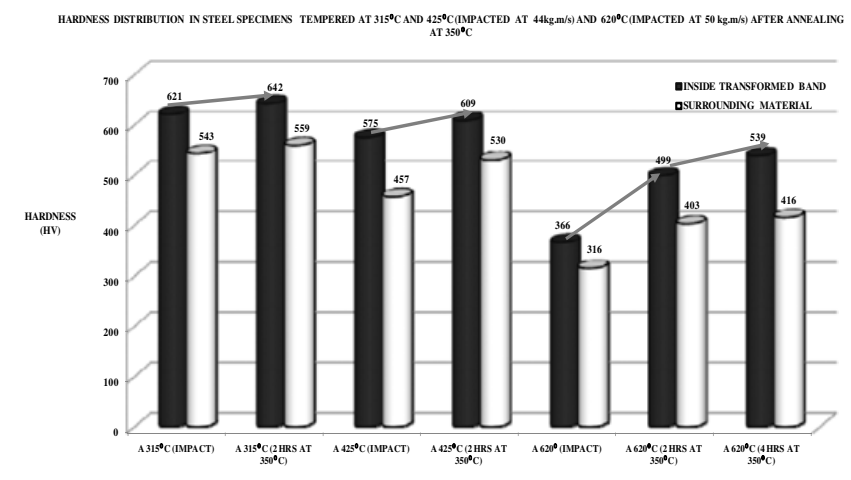

Fig. 4. Increasing hardness during post-impact annealing at $350^{\circ} \mathrm{C}$.

to the formation of distinct and well-developed adiabatic shear bands after impact compared to the shear bands formed in specimens tempered at $315^{\circ} \mathrm{C}$ and $425^{\circ} \mathrm{C}$ for two hours. However, deformed shear bands were predominant in the specimens tempered at $620^{\circ} \mathrm{C}$ for two hours.

Regardless of the heat treatment before impact, amount of deformation, and the time for post-impact annealing, annealing the shear bands at $350^{\circ} \mathrm{C}$ resulted in an increase in hardness of the shear bands and the surrounding impacted material outside the shear bands as can be seen on figure 3 and figure 4.

After post-impact annealing at $350^{\circ} \mathrm{C}$ for 4 hours, the white transformed shear bands remained white after etching and were easily distinguishable from the surrounding impacted materials as shown on figure 3. In addition, hardness of the shear band increased from $366 \mathrm{HV}$ after impact to $499 \mathrm{HV}$ at the same time as the hardness of the surrounding material also increased from $316 \mathrm{HV}$ after impact to $403 \mathrm{HV}$ after 2 hours post-impact annealing at $350^{\circ} \mathrm{C}$. The hardness of the shear band and the surrounding material continued to increase after 4 hours post impact annealing at $350^{\circ} \mathrm{C}$ from $499 \mathrm{HV}$ to $539 \mathrm{HV}$ for the shear band and from $403 \mathrm{HV}$ to $416 \mathrm{HV}$ for the surrounding impacted material as shown on figure 4 .

The steel specimens that were annealed at $650^{\circ} \mathrm{C}$ after impact had decreasing hardness in the shear bands and the surrounding bulk impacted material as can be seen in figure 5 and 6

Post impact annealing for 30 minutes at $650^{\circ} \mathrm{C}$ reduced the hardness of the shear band significantly. Properties 


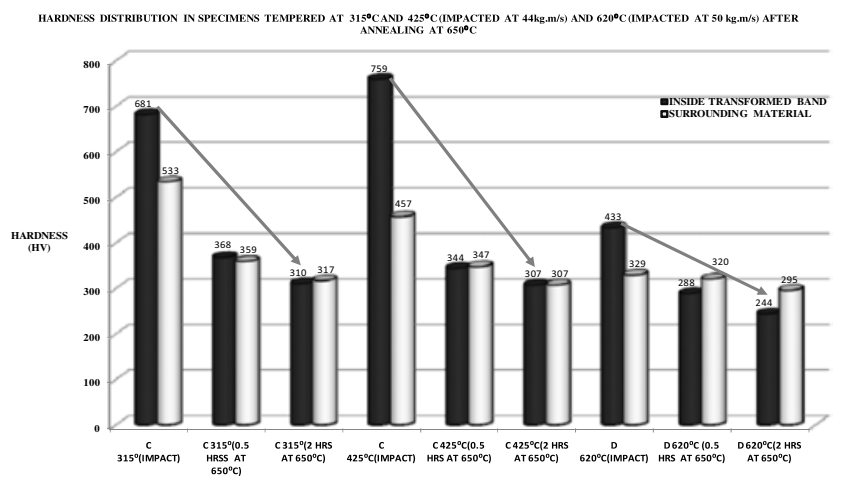

Fig. 5. Decreasing hardness during post-impact annealing at $650^{\circ} \mathrm{C}$.
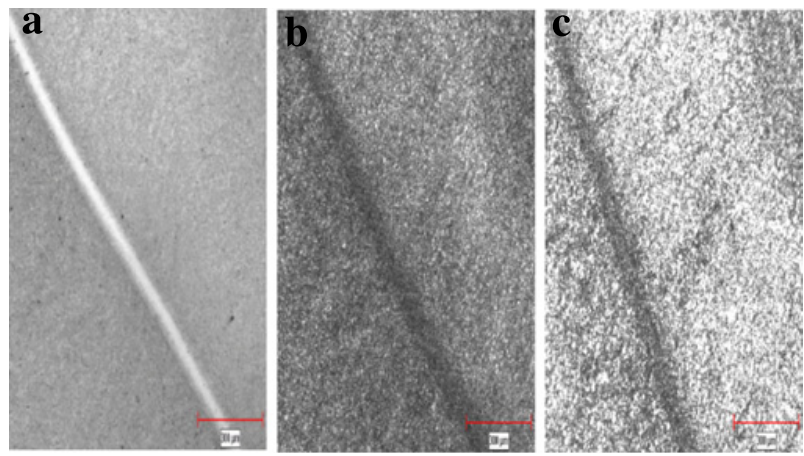

Fig. 6. Steel specimen (a) after impact (b) after $0.5 \mathrm{hrs}$ postimpact annealing at $650^{\circ} \mathrm{C}$ (c) after $2 \mathrm{hrs}$ post-impact annealing at $650^{\circ} \mathrm{C}$.

in the shear band and the surrounding impacted material became comparable after 2 hours post-impact annealing at $650^{\circ} \mathrm{C}$. This was typical of all the steel specimens that were annealed at this temperature after impact regardless of the impact and annealing conditions. These observations demonstrate that this temperature is very important since the shear bands become unstable and begin to disappear. Nevertheless, although post-impact annealing of the specimens at $650^{\circ} \mathrm{C}$ resulted in the shear bands being replaced by a new microstructure that had properties correspondent to that of the surrounding impacted material, there was a 'scar' left by the shear bands in the impacted specimens after annealing at $650^{\circ} \mathrm{C}$. This 'scar' could be used to trace the initial path of the shear bands in the specimens after impact as can be seen on figure 6(c) after 2 hours postimpact annealing at $650^{\circ} \mathrm{C}$.

On the other hand, post impact annealing of the impacted specimen at $850^{\circ} \mathrm{C}$ erased both the properties and the 'scar' of the transformed shear bands in the impacted steel specimens completely. The hardness was reduced to that of the surrounding material and there were no 'scars' left in the impacted specimens as shown in figure 7.

Figure 7 shows that after post-impact annealing at $850^{\circ} \mathrm{C}$, the microstructure of the specimen becomes homogenous with properties comparable to the surrounding impacted material. The observations from the current study demonstrates that adiabatic shear bands are persistent at lower annealing temperatures but become unstable at higher annealing temperatures.

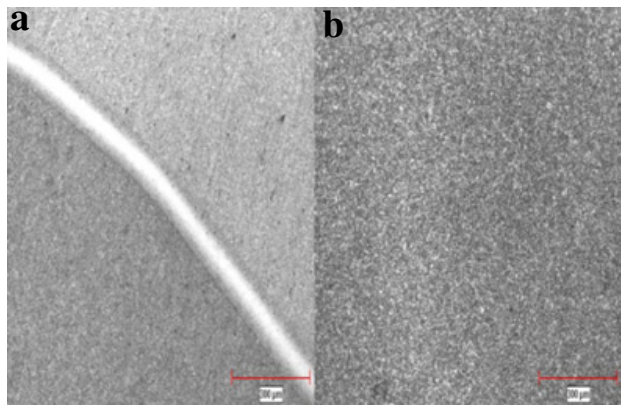

Fig. 7. Steel specimen (a) after impact (b) after $0.5 \mathrm{hrs}$ postimpact annealing at $850^{\circ} \mathrm{C}$.

\section{Discussion}

The mechanism of nucleation and evolution of adiabatic shear bands in metallic materials remains less understood due to the complexity of the problem of formation of these indicators of damage, which sometimes lead to fracture. Recently, it has been suggested that ASBs are mesoscale features, which are two-dimensional, and are caused by thermodynamical nonequilibrium instabilities. Panin [10] has suggested that ASBs are in the same category as dislocations, dislocation structures and disclinations. Bassim [11] has suggested that the apparent features observed microscopically in ASBs resemble those observed in low cycle fatigue with the occurrence of persistent slip bands (PSB) and in ductile fracture with the presence of stretch zones (SZ). In some cases, these features have been related to the macroscopic behaviour of materials exposed to loading leading to fatigue or fracture.

In the case of impact behaviour, the situation is much more complicated. The appearance of the ASB's depends on a number of intrinsic factors, which include the crystal structure of the metal. Thus, adiabatic shear bands are more pronounced and defined in high strength BCC metals, including steels. FCC metals, such as aluminium and copper have less defined ASBs and their appearance is more diffuse due to the plastic flow that these metals exhibit.

Another effect of crystal structure resides in the point of stress collapse when adiabatic shear bands start to initiate. For BCC metals, this point is well defined based on the modelling of Anand [12] and Feng and Bassim [13] while in FCC metals, the initiation of adiabatic shear bands may be triggered in the strain hardening part of the impact sequence due to rapid formation of dislocation structures which act as initiation nuclei [14].

Restricting our analysis to the steel tested, namely 4340 steel which has a BCC structure, the problem is further complicated because the ASBs form by replacing the original tempered martensite microstructure in the narrow bands of ASBs where the strains are very high. This transformation, which involves dislocation mechanisms, grain size reduction and possibly dynamic recrystallization, takes place in very short times and produces the ASBs that are observed.

All these factors render the answer to the extent of the persistence of adiabatic shear bands rather difficult. This present research attempts to provide an initial partial 
answer to the persistence question by showing that appropriate heat treatments at temperatures below the austenitization temperatures may reduce or even eliminate the negative effects of the presence of the ASBs, provided that they have not resulted in initiation of microcracks in the shear bands. Both microscopic appearance and microhardness seem to validate these points and give an initiation proof that materials with adiabatic shear bands can be repaired and reused after an appropriate heat treatment procedure.

The detailed mechanisms of recovery and elimination of the ASBs in BCC metal such as steel are not yet investigated. Mechanisms involving dislocation motion and dynamic recrystallization may hold a clue to the observed phenomenon described in this manuscript.

\section{References}

1. G. M. Owolabi, A. G. Odeshi, M.N.K. Singh and M.N. Bassim, Mat. Sci. Eng A 457 (2007) 114

2. M. N. Bassim and N. Panic, J. Mat. Process. Tech 92 (1999) 481
3. K. A. Zurek, Met. Trans. A 25 (1994) 2483

4. M. A. Meyers, V. F. Nesterenko, J.C. Lasalvia and Q. Xue, Mat. Sci. Eng A 317 (2001) 204

5. M. N. Bassim, J. Mat. Process. Tech 119 (2001)

6. S. E. Shoenfeld and T. W. Wright, Int. J. Solid Structures 40 (2003) 3021

7. M. N. Bassim, M. Bolduc, G. Nazeemuddin, J. Delorme and I. Polyzois, DYMAT 2012, (In press)

8. J. T. Black and R. A. Kohser, "DEGARMO'S Materials and Processes in Manufacturing" $10^{\text {th }} \mathrm{Ed}$. Wiley (2007)

9. R. Nakkalil, J. R. Honnaday and M. N. Bassim, Mat. Sci. Eng A 141 (1991) 247

10. V. E. Panin, V. E. Egoweshkin and A. V. Panin, Proceedings of Mesomechanics (2010) 215

11. M. N. Bassim, Proceedings of Mesomechanics 2011(July 2011) 64

12. Anand, Int. J. Plasticity 1 (1985) 213

13. H. Feng and M. N. Bassim, Mat. Sci. Eng A 266 (1999) 255

14. F. Yazdani, M. N. Bassim and A. G. Odeshi, Procedia Eng 1 (2009) 225 